\title{
Azo Compounds as Green Corrosion Inhibitor for Carbon Steel in Hydrochloric Acid Solution: Corrosion Inhibition and Thermodynamic Parameters
}

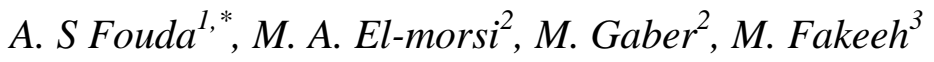 \\ ${ }^{1}$ Department of Chemistry, Faculty of Science, El-Mansoura University, El-Mansoura-35516, Egypt, \\ Fax: +20502202271,Tel: +2 0502365730 \\ ${ }^{2}$ Department of Chemistry, Faculty of Science, Tanta University \\ ${ }^{3}$ Higher Institute of Engineering and Technology, New Damietta, Egypt \\ *E-mail: asfouda@hotmail.com \\ *E-mail: mfakeeh1985@gmail.com
}

doi: $10.20964 / 2017.09 .33$

Received: 28 April 2017 / Accepted: 30 June 2017 / Published: 13 August 2017

The influence of azo compound (L3) 2,4-dihydroxy-5-((5-mercapto-1H-1,2,4-triazol-3yl)diazenyl)benzaldehyde) on the carbon steel (CS) corrosion in $1 \mathrm{M} \mathrm{HCl}$ was investigated using mass loss (ML), Tafel polarization (TP), electrochemical impedance spectroscopy (EIS) and electrochemical frequency modulation (EFM) tests. The protection efficiency (PE) improves with raising the concentration of inhibitor, but lesser with temperature rose. The inhibitor was adsorbed on the CS surface following Langmuir's adsorption isotherm. The electrochemical results showed that the investigated compound doing as mixed-kind inhibitor. Some thermodynamic parameters for activation and adsorption processes were determined and discussed. The inhibition mechanism was debated in the light of the chemical structure of the investigated compound.

Keywords: Corrosion protection; Carbon steel; HCl; Azo compounds; Adsorption isotherm

\section{FULL TEXT}

(C) 2017 The Authors. Published by ESG (www.electrochemsci.org). This article is an open access article distributed under the terms and conditions of the Creative Commons Attribution license (http://creativecommons.org/licenses/by/4.0/). 